\title{
The Development and Care of Spinal Cord Paralysis (1918 to 1986 )
}

Sir George M. Bedbrook, Kt, OBE, OStJ. MS. (Melb)

Royal Perth Rehabilitation Hospital, Perth, Western Australia

The historical development of spinal cord paralysis care includes:

(a) Scientific developments of academic interest.

(b) The growth of community interest plus the education of social groups in rehabilitation and habilitation.

(c) Development of pre-vocational and recreational activities.

(d) Initiation and development of sport, first in therapy then in competition-initially for paraplegics-by 1986 for all disabled or handicapped persons.

(e) Acknowledging those persons who, historically, have played a significant part.

Of paramount importance however must be the 'history' of the individual who, freed from the pessimism and apathy characteristic of the early decades of this century, has emerged into the optimism and successful development of the 8 th decade.

This account will attempt to mention the above as I record the effort of those 'Menders of the Maimed' who carried on the heritage recorded for posterity by Sir Arthur Keith in 1919 in his classical monograph on disability and handicaps. Fundamental observations on the physiology of spinal paralysis, motor and sensory, appeared in that publication.

Henry Head's Studies in Neurology (1920) and those of Georges Guillan and J. A. Barre (1920) are classic in their descriptions of spinal cord injuries and excellent examples of the information then available. These several authors describe the physical symptoms and signs in a group of illustrative cases giving a clear and precise account with diagnostic significance not excelled today. Cheyne and Burghard's Studies (1900) in Spinal Injuries gave details that sadly did little to develop better management.

In Europe as early as 1917 a conference was held in Paris under the Chairmanship of Professor Jean Carmus (on War Injuries of the Nervous System) who advocated special centres, and one speaker, M. Hugaret, advocated aseptic intermittent catheterisation, and Mme De Dejerine advocated functional reeducation. In Germany prior to 1939, some Neurosurgeons such as Foerster in 


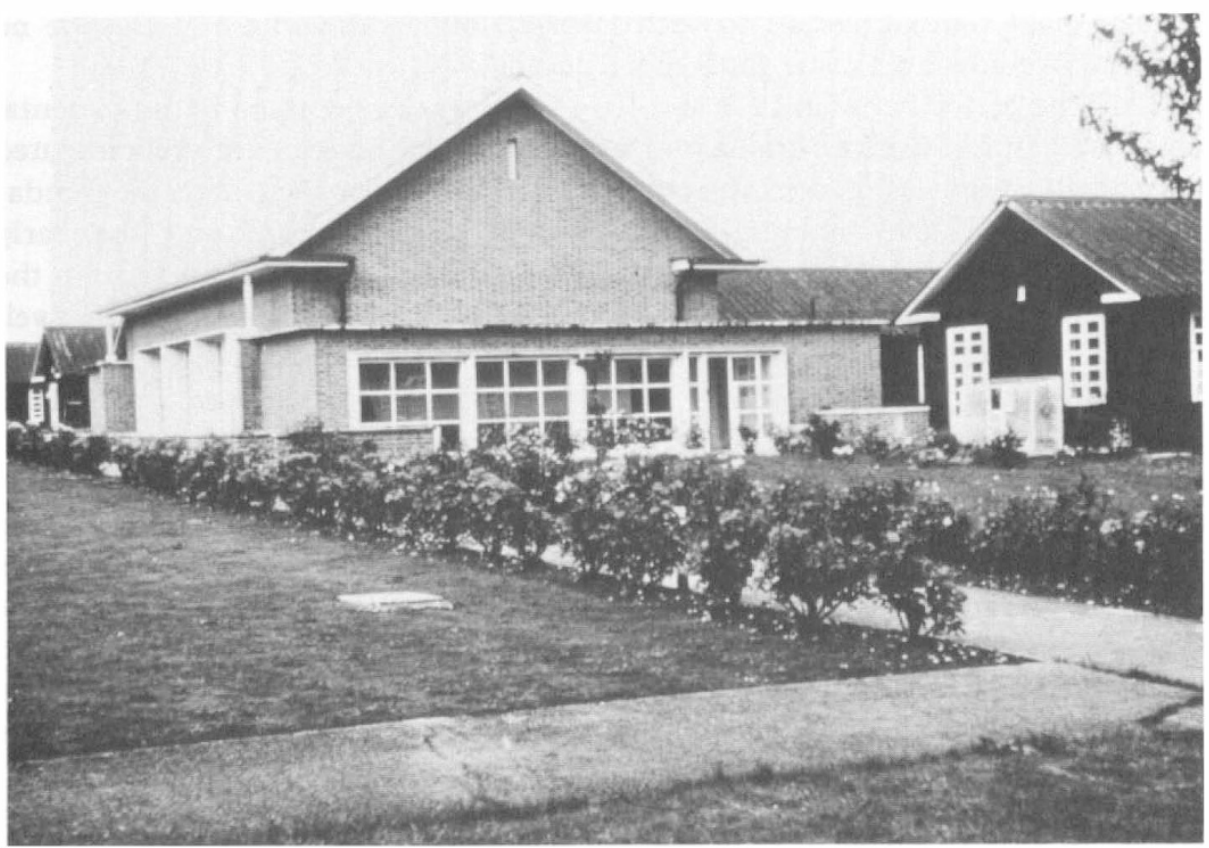

Figure 1 Stoke Mandeville Hospital, National Spinal Injuries Unit, Aylesbury, Buckinghamshire, England.

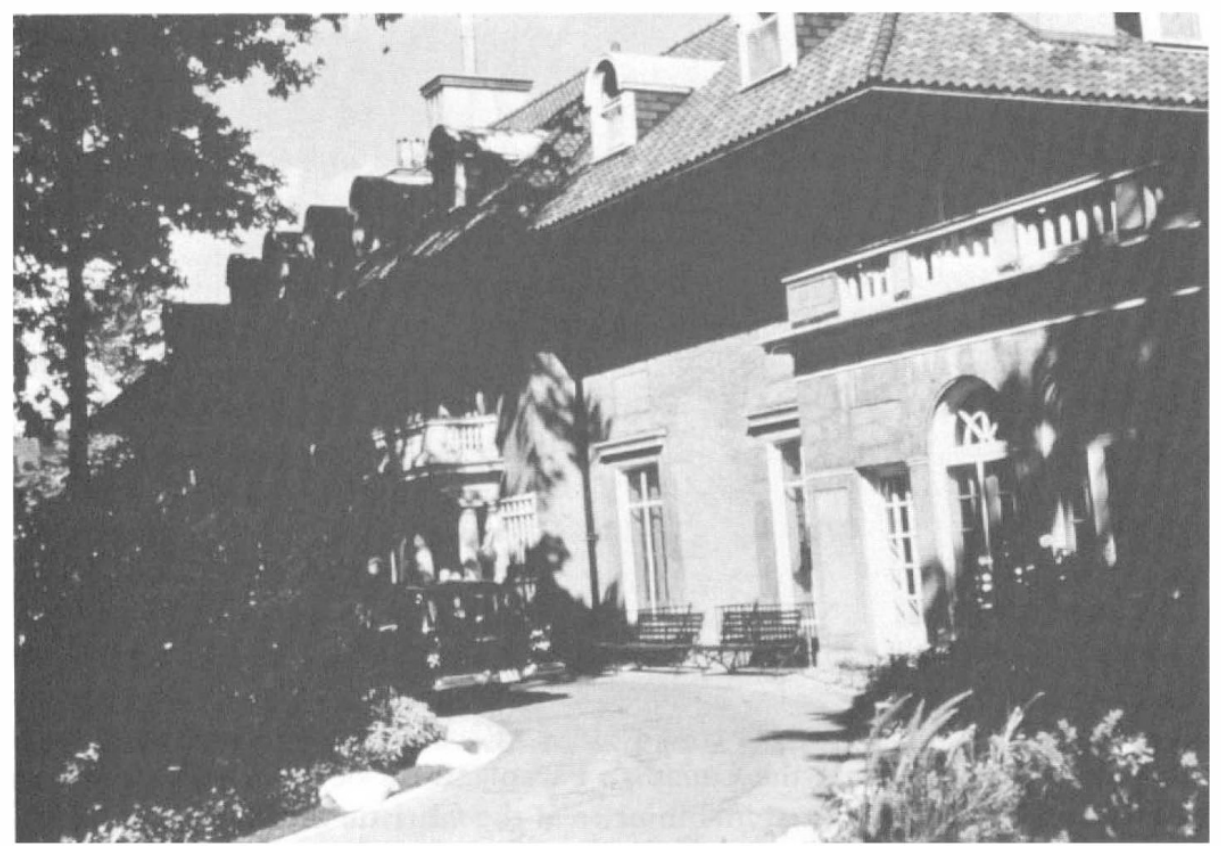

Figure 2 Lyndhurst Lodge in Toronto, Canada. 
Breslau paid some attention to such injuries, but in the whole of Europe no constructive advances came for 2 more decades.

Thus the period between 1918 and 1944 only saw development in fundamental neurology and in urinary drainage. Despondency in patient care predominated universally despite the rise of great orthopaedic hospitals where the fundamentals of excellent nursing, good physical rehabilitation and the early development of workshops with aftercare organisations existed largely from the work of Robert Jones (1921), Girdlestone and their disciples. Despite the well documented paper by Buzzard and Sarjent (1921) [in 'Orthopaedic Surgery of Injuries' edited by Robert Jones (1921) where prevention of contractures and bedsores were discussed and where urinary care was described], application of these principles was not applied to spinal cord injuries.

Except for Donald Munro (1943, 1952) and Hansen (1952) in Boston (see page 175) and thoughtful consideration by some urologists and neurosurgeons on both sides of the Atlantic, the management of this categorical speciality was stagnant because of the totally pessimistic attitudes of the medical profession. In North America, E. H. Botterell, Consultant Neurosurgeon to the Canadian Army, on returning to Canada in 1942-43, suggested a concentration of effort and invited Dr Al Jousse to take charge. In the U.K., George Riddoch and Geoffrey Jefferson conjointly with Hugh Cairns invited (via the Ministry of Pensions) Ludwig Guttmann to open a comprehensive care unit at the Ministry of Pensions Hospital, Stoke Mandeville. The stage was set to show more development in 3 decades than for previous known time in this grossly neglected area. Such worldwide effort as will now be described had the effect of spearheading development in other disabilities: head injuries, hemiplegia, chronic neurology, intellectual handicaps and cerebral palsy, particularly as poliomyelitis, skeletal tuberculosis and staphylococcal bone infections came under control and almost disappeared.

The period between 1918 and 1945 is well summarised in publications by $T$. B. S. Dick (1969) and L. Guttmann (1973). Donald Munro's contribution in the fourth decade $(1943,1952)$ was substantial and well documented, yet 'medicine' did not respond to the challenge even when he recorded the first civilian group, showing that rehabilitation of neuropathic visceral dysfunction was possible together with $45^{\circ}{ }_{0}$ success in physical rehabilitation. The 1 st of February 1944 was the turning point in the United Kingdom with the establishment of the Stoke Mandeville Centre (Fig. 1), whilst in North America the 15th of January 1945 saw the establishment of Lyndhurst Lodge in Toronto (Fig. 2). In Canada the real impact came through two paraplegics (one resulting from a horse injury-James Daroux, the other-John Counsell from the Dieppe Raid) and a philanthropist-Lew Wood with two neurosurgeons-W. Cone and E. H. Botterell.

The group prevailed on the Veterans' Affairs Department in Canada, not just to park the cases in a home, but to embark on a special programme that Daroux and Counsell had set themselves. Thus late in 1944, Lyndhurst Lodge was renovated and opened and the Canadian Paraplegic Association was formed on May 10th, 1945. Wards for spinal injuries at the Christie Street Veterans Hospital preceded this development. The Association then played a very great role in medical development in Canada. In the U.S.A. the Veterans' Administration 
quickly followed in 1945 and set up eight units. The first being at Birmingham General Hospital, Vun Nuya, California, with Ernst Bors involved. Ernst Bors was a great pioneer in a Veterans' Administration Unit in California; whilst Herbert Talbot similarly gave much service in the Boston Veterans' Administration Unit. Thus the initial development of a great surge forward in more adequate care for spinal paralytics came after Dr Munro's effort of 1943.

Guttmann (1973) and Dick (1969) record how some spinal units, set up in the U.K. early in the 1939-45 War, failed by not applying fundamental rules enunciated by Guttmann in 1944. Still fundamental they are:

(a) Management of a unit by an experienced physician who is prepared to give up part, or all, of his own speciality.

(b) Sufficient allied health professionals, e.g. nurses and therapists to cope with details of care.

(c) Technical facilities to establish workshops and vocational outlets.

(d) Attention to social, domestic and industrial resettlement.

(e) The regular aftercare, or extended care, over the lifetime of each individual.

Until such requisites are available, no service will give sufficient care. The long-term problems of spinal paralytics in the 1920s to the 1930 s were horrific and appalling and regretfully of great disinterest to the medical profession. As a student in Melbourne (1939-1944) this author remembers the use of plaster beds and the sudden disappearance of paraplegics from acute hospitals-to the mortuary, or worse-to a geriatric institution.

The urgency of war thus once again drew attention to a neglected area of medicine where piecemeal attention was universal and where complications were dominant, causing death within 6 to 8 weeks. Comprehensive, multidisciplinary application of fundamental principles were to produce results not dreamed of in 1920. Even now, as the 80s are entering their latter stage, piecemeal care has not universally disappeared (even in developed countries).

In the last 4 decades two persons have had the greatest individual effectLudwig Guttmann's story so internationally shattering, has been told and retold. In the First Guttmann Lecture I attempted to give a clear picture of this extraordinary man (1982). His place in history has been well summarised (Goodman, 1986). How he came to the U.K., worked in Peripheral Nerve Units with no clinical responsibility until 1943 when he was invited by Riddoch (with Cairns and Jefferson) to establish the Stoke Mandeville Service, first for Service personnel and then by 1948 for civilians. The birthday volume of Paraplegia (1969) Vol. 7, emphasises these developments.

Donald Munro's (1943, 1952) effort in Boston needs especial emphasis. His pilot study of 1943 at the Boston City Hospital showed the possibilities, but it was not until 1952 when he established the first civilian unit in the U.S.A that his views were accepted. In 1952 he said in his textbook (1952) that civilian units could be counted on one hand in the U.S.A. Together with Mr Stanwood L. Hansen (1952) of Liberty Mutual Insurance, he could show the tremendous financial saving that such units would have-medical and hospital costs were slashed by at least $200-300 \%$. Their efforts finally resulted in the present well-established regional system of Spinal Cord Injured Centers. Donal Munro 
deserves more recognition than is usually accorded him. A quiet academic who in the 1930s showed the path that ultimately became well blazed by others.

Spinal man can be precisely defined timewise:

$\begin{array}{cll} & \text { Past } & \begin{array}{l}\text { Pre Guttmann } \\ \text { Guttmann } \\ \text { Post Guttmann }\end{array} \\ & \text { Present } & \begin{array}{l}\text { Comprehensive Units } \\ \text { Extended Care }\end{array} \\ & \text { Future } & \begin{array}{l}\text { Prevention } \\ \text { Fundamental Research }\end{array}\end{array}$

The 18th of March, 1980, closed the Guttmann Era as he passed into history, leaving a heritage for continuance. Spinal man came far in those years and has already advanced further since his death (1985).

A number of significant developments can be summarised for the last 4 decades:

(1) Comprehensive Units.

(2) Advances in medical science including pathology and prevention.

(3) The International Medical Society of Paraplegia, The International Stoke Mandeville Games and other international groups.

(4) Community activities, after-care and now prevention.

\section{Comprehensive units}

Within a few years of the initiation of spinal units in U.K., Canada and the U.S.A., there was a proliferation of units, particularly in the Veterans' area in America. Borsa (1967) great European/American pioneer, in his interesting article in a symposium on organisation, stressed the flexibility needed in the surgeon to accept such unorthodox methods as were succeeding so brilliantly. Little did George Riddoch dream of the revolution that would quickly follow in the decades from 1944 to 1964.

In Germany and France development in the 1950s was rapid. The first unit in Germany was probably that at Bochum. Names such as Arens, Böhler, Neubauer, Kreusch, Lemberg Ziechold and Bunkle Dela Camp, were associated with development. 1956 saw Dr Fred Meinecke involved and then by 1965 Professor Volkman Paeslach at Heidelberg. In France, Pelat, a urologist at Hopital des Invalides, Paris, started a unit in early 1950. Dr Gressind, a neurologist in Garches-Willot in Burck, Benassy in Garches and Dollfus in Mulhouse in the 1960s. This vanguard was quickly followed by others throughout Europe. In Belgium, Houssa of Hospital Bruggman, established a service early in the 1950s whilst Pool of Holland did likewise as both these countries supported the Games development.

By the end of the 7th decade there were active spinal injury units all over Europe, U.K., Ireland, Germany, France and Switzerland, so that Paeslach, in 1967, could report six units in European University cities-Brussels, Warsaw, Geneva, Heidelberg, Cologne and Basel. Meinecke reported the first unit in the mining area of Bochum in 1952. This was to develop into a well co-ordinated system of units for all citizens of West Germany. In Australia, in 1954, the Royal Perth Hospital in Western Australia on the advice of Col. L. E. Le Souef, 
started a unit with the then Dr G. M. Bedbrook, with other centres in Sydney, Adelaide and Brisbane by the end of the decade. Melbourne followed in 1956. A unit was started in New Zealand by the early '60s and in South Africa in 1960.

The real advance that Ludwig Guttmann was able to achieve in 1943 when Stoke Mandeville was conceived, was that it should be an autonomous unit; the same doctors looked after patients from the earliest possible moment after injury. This ideal was not always to be achieved, many units started within orthodox units, e.g. Heidelberg in Germany, Sheffield in the United Kingdom, Midlands (Oswestry) U.K., Perth in Western Australia, and Adelaide in South Australia, developed from orthopaedic units, whilst others developed from neurosurgical services, e.g. Toronto in Canada, Edinburgh in Scotland, Royal North Shore Hospital in Sydney, Australia, Pinderfield in the U.K. and many American centres. Some American services developed from general rehabilitation units, e.g. Chicago in 1968 and Bellview in New York, Prince Henry Hospital in Sydney, Dublin in Ireland and also Brussels in Belgium and in Holland. Most units achieved autonomy gradually, but the one physician one patient principle so strongly advocated by writers Guttmann (1973), Young (1982), Bedbrook (1985) and Botterell $(1977,1978)$ has still not always been given strong executive action. Development of many of the spinal injury services came because of individuals (numberless and thus nameless) who are really the inheritors of Arthur Keith's Menders of the Maimed (1919). 1968-1969 saw units develop in Austria and Spain, but it was not until 1964 that Rancho Los Amigos developed a civilian unit on the West Coast of the U.S.A. whilst the 1st Regional Service-of a discrete nature is recorded as occurring at the Good Samaritan Barrow Institute, Phoenix in 1970.

The successive development of 20 spinal cord injury systems for civilians within America is well described by John Young and his associates (1982) in the Spinal Cord Injury Statistics. India, Taiwan, Thailand and Burma followed with spinal units in the late ' 70 s early ' 80 s, whilst Singapore developed its spinal injury service in the mid '70s at the same time as Indonesia. Most of the Far East countries came directly under the influence of Australia and New Zealand with some Canadian assistance. South America is yet to develop independent spinal injury units, as is Scandinavia. Japan saw a great surge forward in vocational and social care after the 1964 Paralympics. Tokyo, in 1965 and Beppu in 1966, saw the development of such services. Spinal services have now developed in many of the university cities of Japan, particularly in places like Tokyo, Chiba and Tokushima, whilst the Labor Corporation Center at Iizuka City is noteworthy. This came about largely through the initial effort of $\mathrm{Dr}$ Tamikazu Amako, Honorary Professor at Kyuschu University who was Dr Yukata Nakamura's teacher. Nakamura himself played a very big part in sport and vocational developments with the extraordinary development in industry of the Japan Sun Industries. Here was a good example of the tremendous influence, repeated regularly, of the International Stoke Mandeville Games and later the International Medical Society.

Comprehensive Services are really only comprehensive with the development of extended care. This seems to have been better developed in some areas and is still the challenge. These initially developed in the U.K., Western Australia and in India at the army unit in Puna, whilst in European countries the general 
welfare system for disabled accepts these responsibilities. In America, effort towards extended care and attendant care has been made, particularly in Berkeley, California. This story is yet to be told as the future decades unfold.

In 1986 over 100 spinal units exist, all operating in a similar manner, and as David Burke (1985) from Melbourne, showed statistically, most spinal cord injury units are managing patients conservatively, though with some difference of care in some areas. Comprehensive services developed rapidly in the decades of 1944-64 but even more so in the decades 1965-85.

\section{Advances made in the scientific study of traumatic paraplegia and tetraplegia, including prevention and paramedical professions}

Medical literature between 1920 and 1945 was divided concerning the treatment of the neuropathic bladder and to prevent ascending infections whilst combining a statement of gross pessimism as far as life was concerned. No scientific studies were published except those in relation to neurological observations. Some papers were presented on the pathology of gunshot wounds and spinal cord injuries in the 1920s (Buzzard \& Sargent, 1921). Most of the writers, including Thompson Walker, mentioned by Dick (1969) in both 1917 and 1937, estimated an $80^{\circ}{ }_{0}$ total mortality from World War I. It is apparent from the American literature that American paraplegics fared no better even up to 1934, when writers such as Nash and Connors noted a death rate of over $80^{\circ}{ }_{0}$. Brock's monograph of 1940 though describing more pathology, made no advance in application. Amako, in Japan, described some pathology and its application as early as 1943 including war injuries. Marc Maury wrote the first French Medical Thesis on Spinal Cord Damage in 1950 and started to publish from Fontainebleau in 1953 a series of papers on care and management as well as being responsible for training other physicians.

No pure scientific studies were published until Tribe in 1963 published his excellent monograph on the causes of death in the early and late stages of paraplegia when he could report that he found only three papers between 1945 and 1963 dealing with purely pathological matters allowing careful comparison from adequate findings. Causes of death, for example, between paraplegia, nontraumatic and traumatic, were poorly differentiated. All cases apparently died of complications rather than the primary cause. In 1962 a monograph entitled Basic Research in Paraplegia edited by French and Porter (1962) described some advances in scientific matter related to regeneration and spinal reflexes. In 1963 some excellent papers occurred on the early scientific studies of radicular motor innervation as summarised by the French writers, including Grosseord, Buzacoux Maury and Barthes (1963) in their studies of motor metamerisation of the upper limbs. Lionel Wolman's contribution (1963) to the neuropathology of traumatic paraplegia and his excellent application of such neuropathology had to wait till the early 1960s, although Ludwig Guttmann's monograph on the modern therapy of paraplegia (1973) in the history of World War II was the most significant early monograph summarising the total concept of the new scientific approach to the management of paraplegia and tetraplegia. This Journal, Paraplegia was first published in 1963 after the International Medical Society of Paraplegia commenced in 1960. The first publications recorded the 
multiplicity of complications and their difficulty in management but allowed the therapeutic side to be given more dialogue and more emphasis. Matters of social importance and resettlement were carefully emphasised and widely discussed. An early symposium on the wheelchair foreshadowed the development that is now occurring in technology and rehabilitation engineering. Some of these topics discussed and recorded in Paraplegia were amongst the first scientific programmes ever to be discussed in relation to the disabled and certainly would not have been given a place in a medical journal.

The scientific subjects considered by the International Body have been extremely varied, concentrating perhaps at first on development of better genitourinary care, particularly as technology advanced. Bioengineering (or Rehabilitation Engineering) featured regularly whilst neurology and physical methods of rehabilitation were commonly discussed. The old argument of surgical care (now 150 years old) featured regularly. The benefit such meetings and those of national bodies has been and are, is enormous in every way. Combined meetings of groups have occurred twice with the Veterans Administration (V.A.) group in the U.S.A., more of such are now planned.

By the end of 1965 and into the early '70s, the Journal of Paraplegia played a major and significant part in assisting scientific application to management. By 1965 the value of trained personnel in the early collection of casualties and their early admission to spinal units was well recognised. Recently, workers have suggested that some 20 to $25^{\circ}{ }_{0}$ of spinal cord injury patients deteriorated after injury because of poor handling. The tremendous variety of injuries and associated injuries in traumatic paraplegia was well recorded in the late '60s. So the application of knowledge proceeded. Significant textbooks (Guttmann, 1973; Vinken \& Bruyn; Pearman \& England, 1973; Guttmann, 1976; Bedbrook, 1981, 1984) became available towards the end of the '70s. The most detailed is that of Vinken and Bruyn in their Handbook of Clinical Neurology, Volumes 25 and 26. The content of these was contributed to by a galaxy of authors from all over the world and is the most authoritive scientific publication on spinal cord paralysis.

Two phases in the development of the scientific process can be recognised. Between 1920 and 1963 studies on the grossness of complications and some studies on the physiology of the bladder dominated. In the late ' 60 s much more basic information appeared on pathology, physiology and management with studies in access requirements plus elucidation of the problems associated with urinary tract infection. Now, not only how to treat urinary tract infections, but how to prevent them so that secondary prevention has emerged to be at last dominant in care (Pearman and England, 1973; Guttmann 1973).

By the late '70s and early '80s, tetraplegic care became more dominant in the scientific material. Increasing technology applied to the management of tetraplegia received increasing interest in both the social and the resettlement problems associated with spinal cord injuries. Allied professionals in nursing and early physiotherapy during World War I seemed to have applied similar management techniques to skeletal injuries but no attempt was made to apply similar principles to spinal cord injuries. The history of medicine in World War I shows how even simple injuries developed the most horrific complications that physical therapists then had to treat, e.g. joint contracture, myasthenia, and 
infection. Bed sore and wheelchair sore management has changed over the last 3 to 4 decades from vigorous conservative care, allowing healing to a combination of debridement, thorough cleaning, working out synergistic antibiosis for use with plastic repair and principally to total prevention. The evolution of the wheelchair and the establishment of wheelchair and pressure clinics with rehabilitation engineering now makes it possible to reduce the readmissions for sores by over $50 \%$ and the time in hospital for such sores by $50 \%$.

Early work in the late '40s in maintaining physiological bowel and bladder function by intermittent techniques (Guttmann, 1973) has been followed now by urodynamics, a development in physiology undreamed of in the '20s when only methods of bladder drainage were dominant. Until infection control really became possible by Guttmann and Frankel (1973) and then Pearman (1973), urinary infection remained $100^{\circ} \%$. Even today it is so in many areas in well developed countries as well as in poorly developed areas. Not because the knowledge is missing, but because the application is not enforced, allegedly due to insufficient staff. In medicine (in distinction to commerce) it is difficult to get administrators and politicians to grasp the fact now well proved that efficient well-staffed care is also the most economical (Munro, 1952; Hansen, 1952).

Paraplegia, like other disabilities, is 'people' orientated which is yet a further fundamental concept that Ludwig Guttmann managed to convince Riddoch about in 1943, so that adequate nursing staff were immediately available. Today it is accepted that only with adequate nursing and therapy staff can the details of care be undertaken. Slowly, more people are being trained in post graduate courses. Nurses (Bedbrook, 1981, 1984) play a dominant role sometimes overlooked today by those professionals whose attitudes are related to the highly motivated patient or to technical procedures. Factually, statistics show that over $50 \%$ of spinal paralytics are not highly motivated and need constant attention.

The development of other therapists-physiotherapists, occupational therapists, and social workers etc. is the subject of a separate communication. Together with engineers, these people are harnessing the function that remains to enable the disability to be reduced to a handicap.

\section{Development of the International Medical Society of Paraplegia International Stoke Mandeville Games}

Whilst sport has been used in some disabled groups such as amputees and for the blind for many years, to introduce sport to spinal paralytics was, in 1944, a major and very unorthodox move. Introduced in the early days of hospital care at Stoke Mandeville and in North America, competitive sport developed from an idea that Sir Ludwig Guttmann (1976) had when with T. S. Hill, physical instructor at Stoke Mandeville. He attempted to play wheelchair polo. It became apparent that the very paralysis of the lower limbs would be an advantage in such activities. Wheelchair basketball started in 1945 along with archery and table tennis. Thus, on the 28th of July, 1948, the Stoke Mandeville Games were founded as the Olympics were opened in London.

In 1949 a journal called The Cord recorded Guttmann (1976) as saying that this event would be truly international and the Stoke Mandeville Games would 
achieve world fame as the disabled persons' equivalent of the Olympic Games. That dream has come true as history shows nearly 40 years later. The success of such games not only increased activities such as competitive sport, but also increased the world knowledge of the abilities of spinal paralytics and certainly stimulated the formation of the International Sports Organisation for the Disabled (ISOD). The Stoke Mandeville Games (planned to be held every 4th year in the country of the Olympics) first became international in 1952 with Dutch participation. The games were held in: Rome 1960; Tokyo 1964; Israel 1968; Heidelberg 1974; Holland 1978; Toronto 1982 and Stoke Mandeville in 1984.

Numbers increased and so did the interest and public relations in each country. In the U.S.A. the Pan American Games, in Europe the European Games (since 1957), in the Pacific the Far Eastern and South Pacific (FESPIC) Games since 1975, were started. The British Commonwealth Games Series, held in 1962, 1966, 1970 and 1974, were eventually replaced by the Far Eastern Games. The award of the Fernleigh Cup by the Olympic Committee in 1956 when the Olympic Games were held in Melbourne was a singularly great honour. The games, organised under a medical and functional classification by neurological testing, showed the world, under their symbol of intertwining wheels of friendship, unity and sportsmanship, that the spirit of man is indomitable (Fig. 3).

With the introduction of sport competitively and internationally by 1952, group scientific meetings became possible. Initially each year, team doctors and therapists met for discussion with post graduate studies being possible in the major areas of the U.K., Canada and the U.S.A. In Australia the Royal Aust-

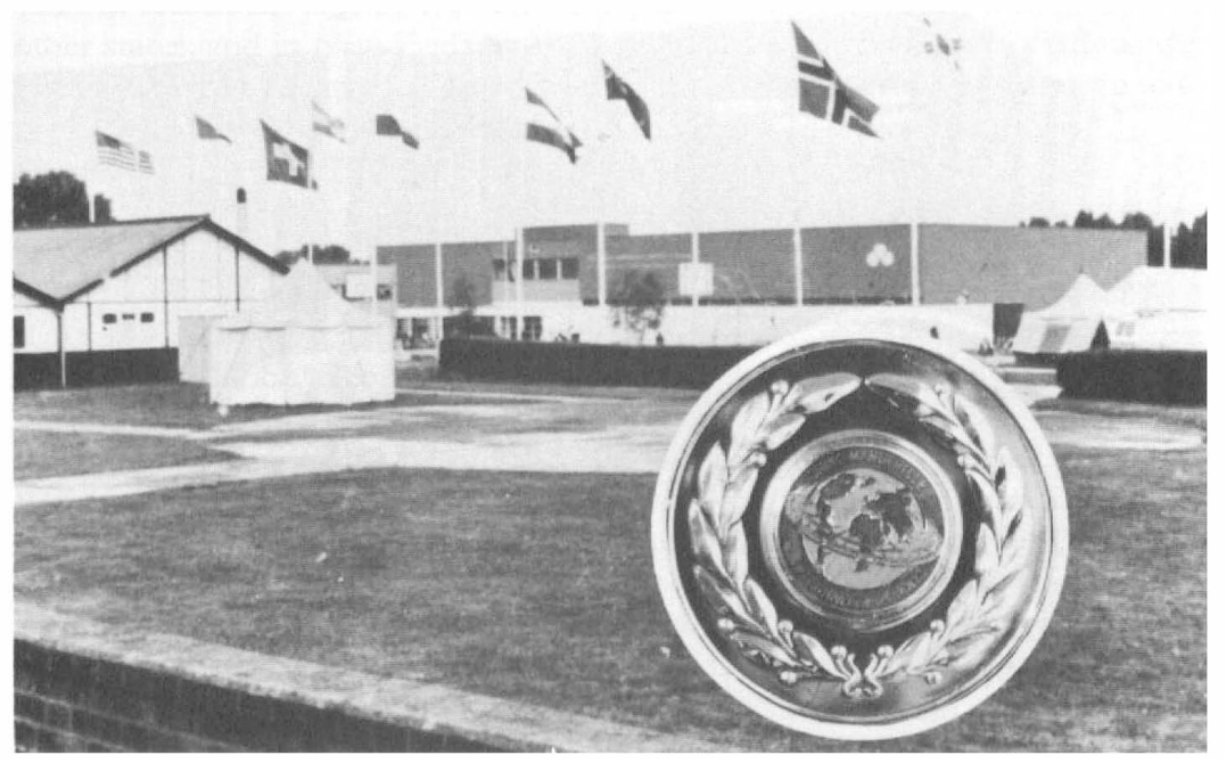

Figure 3 The Sports Stadium for Games for the Paralysed and other disabled at National Spinal Injuries Unit, Stoke Mandeville Hospital. The insert is the Games Medal and symbol. 
ralian College of Surgeons met in Perth in 1958 for a small symposium at the then 4-year-old spinal unit.

In 1960 the International Medical Society of Paraplegia was founded following a suggestion by Houssa of Belgium, with doctors mainly travelling with sports teams. Ludwig Guttmann was first President, followed by Talbot in 1969, Tricot in 1973, Paeslach in 1977, Bedbrook in 1981 and Rossier in 1985. By 1963 the Society achieved its founding aim of increased communication by publishing the journal called Paraplegia whose first numbers reflect the increase in scientific interest in this neglected area.

With the inauguration of the International Medical Society for Paraplegia greater dialogue occurred, both in the U.K. and internationally. This helped in early admission of spinal paralysed to all units-Service and Civilian; the former being slow to take cases early after injury.

Numbers of international meetings steadily increased, initially held with the Games and every second year in the U.K., and then away from the Games to allow for greater participation by professionals (Fig. 4).

Gradually national professional groups have arisen. Today the following groups exist: The American Spinal Injuries Association; The American Paralysis Association; The Japanese Medical Society of Paraplegia; The Indian Medical Society for Paraplegia; The Far Eastern and South Pacific Group for the study of Paraplegia; The German Paraplegic Society; and the International French Speaking Spinal Cord Injuries Study Group (AFIGAP). Recently, an Italian Society was formed. Thus the professional interests of multidisciplinary

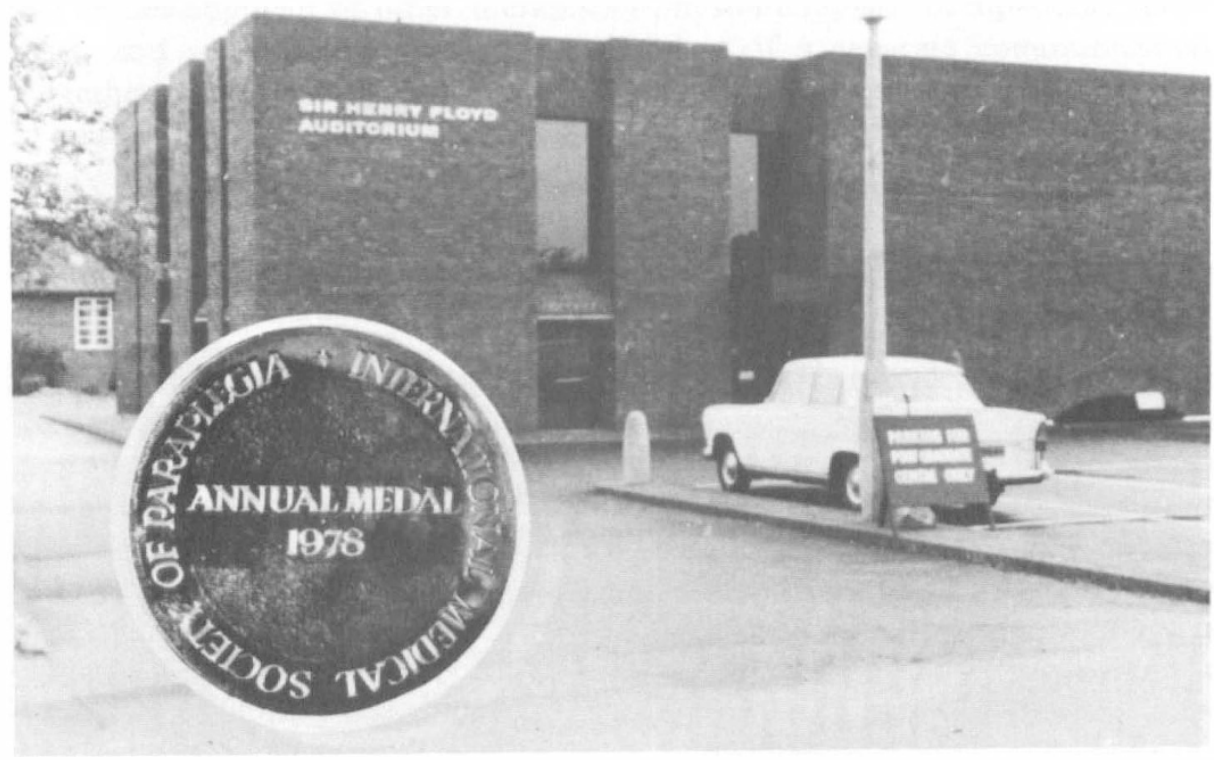

Figure 4 Post graduate Centre, Stoke Mandeville Hospital. The Silver Medal of the International Society as insert. 
staff in the various national areas has slowly been fulfilled to the benefit of spinal paralytics in each country.

\section{Associations and societies}

In the 3rd decade of this century the whole subject of physical and intellectual disability was fostered, not by medicine, but by the voluntary bodies such as Crippled Childrens' Associations. In the 5th and into the 6th decade there occurred a great formation of bodies that were to help very considerably with medical and social welfare, vocational and educational aspects of restoration for spinal cord injury patients. Some of these had greater effect than others. In 1948 there existed a group who published the journal The Cord.

The first major body was the Canadian Paraplegic Association formed by Charter on May 10, 1945, after great effort by John Counsell and his associates. Originally this body had great influence in establishing comprehensive units throughout Canada with its many (10) divisions. Latterly, the Canadian body has concentrated more on the community welfare problems rather than the medical, similar to bodies such as the Order of St John of Jerusalem and the British Red Cross. Immediately after the World War, Servicemen's Associations helped. Lyme Green Settlement at Macclesfield and the Thistle Foundation in Edinburgh, Scotland, are good examples of exservice groups. Veterans' Associations played a great part in the U.S.A. and the National Paraplegia Foundation ultimately became the National Spinal Cord Injuries Foundation with chapters in many states. General associations akin to Rehabilitation International have also played a big part. In Scandinavia the Norwegian Association of the Disabled is a good example, campaigning politically for comprehensive spinal units. In 1957 in Australia, first in Western Australia, then Melbourne and Sydney and other states, and in New Zealand, paraplegic and quadriplegic associations were formed for the life time care and assistance in symbiosis with and in conjunction with the comprehensive units in each area.

In the U.K., the Scottish Paraplegic Association was formed in 1960. It has for many years been very active in community matters for spinal paralytics. Whilst disabled sports were developed in England, the Spinal Injuries Association was formed in 1974 to fill a vital gap therein for information, co-ordination and political advancement.

In South Africa, George Domesses' excellent book (1982) tells the story of a more general body which developed out of a Crippled Children's Group 'Cripple Care' which has helped and benefitted many spinal paralytics. In Japan the emphasis has been slightly different. After the 1964 Games vocational centres appeared in Tokyo and Oita (Beppu) with social community structures. The Japan Sun Industries fulfill a major role in vocational, recreational and community activities. In Switzerland, Basel, the Swiss Paraplegic Foundation, founded in the early 70s, a fund raising body, raises money by membership. This body has sponsored the Swiss Paraplegic Association and plans more facilities and welfare for spinal paralytics.

Communities around the world are accepting their responsibility for continuing care (1984). The development has been astounding. The benefits to 
spinal man are not calculable in terms of reduced disablement and finance. History has galloped along in this categorical area.

\section{References}

BEDBROOK GM 1981 Care and Management of Spinal Cord Injured. Springer Verlag, New York BEDBROOK GM 1982 Ludwig Guttman-Man of an Age. Paraplegia 20:1-17

BEDBRooK GM 1984 Lifetime Care of the Paraplegic Patient, Churchill Livingstone, London.

BEDBROOK GM 1985 Spinal Man-Lee Oration. Fournal Western Pacific Orthopaedic Association 22:1-10

Birthday Volume 1969 Sir Ludwig Guttmann. Paraplegia 7:143-172

Bors E 1967 Organisation of Spinal Units, July 1967 Scientific Meeting Paraplegia 5:115-187

BotTerell EH et al 1978 Acute Cord Injury, Parts I \& II fournal of College of Surgeons of Edinburgh 23:56-57, 107-116

Botterell E. Jousse AT, Krausas, et al. 1977 A Model for the Future Care of Spinal Cord Injured. Canadian fournal of Neurological Science 2:361-380

BROCK S 1940 (Editor) Injuries of the Skull, Brain and Spinal Cord, Williams and Wilkin

Burke DC, Burley HT, Ungar GH 1985 Data on Spinal Injuries Part I, 1985, Collection \& Analysis of 352 Consecutive Admissions. Australian $\mathcal{E}$ New Zealand fournal of Surgery 55:3-13

Burke DC, Burley HT, Ungar GH 1985 Data on Spinal Injuries Part II, Outcome of the Treatment of 352 Consecutive Admissions, Australian $\mathcal{E}$ New Zealand Fournal of Surgery p. 377-382

Buzzard EF, SARgent P 1921 Injuries of the Spine, Orthopaedic Surgery of Injuries 2:237-359

Dick TBS 1969 Traumatic Paraplegia, Pre-Guttmann. Paraplegia, 7:173-178

Domisse G 1982 To Benefit the Maimed. S A Orthopaedic Association and National Association for Cripples in South Africa

FRENCH J, PORTER R 1962 (editors) Basic Research in Paraplegia. Charles Thomas

Goodman S 1986 Spirit of Stoke Mandeville-The Story of Ludwig Guttmann. Collins

Grosseord A, Buzacoux J, Maury M, et al. 1963 Studies on Motor Metamerisation of the Upper and Lower Limbs. Paraplegia 1:81-97

Guillan G, Barre JA 1920 Travaux Neurologeques de Guerre. Masson \& Co

Guttmann L 1973 Spinal Cord Injuries, Comprehensive Management and Research. Blackwell Medical Publications, p. 5-8

Guttmann L 1976 Textbook of Sport for Disabled. University of Queensland Press

HANSEN SL 1952 The Cost of Medical Care in Paraplegia and How It May Be Modified by Rehabilitation Services. In: MUNRo D (ed) Treatment of Injuries of the Nervous System. WB Saunders, Philadelphia

HEAD H 1920 Studies in Neurology. 2:406

JONES R 1921 Orthopaedic Surgery of Injuries. Volume 2

KeITH A 1919 Menders of the Maimed. Oxford Medical Publications

MunRo D 1943 Thoracic and Lumbosacral Injuries: A Study of 40 Cases. Fournal of American Medical Association, Vol 122:1055-1063

MunRo D 1952 Treatment of Injuries of the Nervous System. WB Saunders, Philadelphia

Pearman J, England E 1973 The Urological Management of the Patient Following Spinal Cord Injury. Springer Verlag

TrIBE CR 1963 Causes of Death in Early and Late States of Paraplegia. Paraplegia 1:19-46

VINKEN PJ, BRUYN GW Handbook of Clinical Neurology, Injuries to Spine and Spinal Cord. Parts I \& II, Vol 25 \& 26, New Holland Publishing Company

Watson-Cheyne W, Burghard FF 1900 A Manual of Surgical Treatment Part IV. Longman Green \& Co

Wolman L, 1963 Neuropathology of Clinical Neurology. Paraplegia 1:233-251

Young JS, Burns PE, Bowen AM, et al. 1982 Spinal Cord Injury Statistics, Experience of the Regional Spinal Cord Injury System. Good Samaritan Medical Centre, Phoenix, Arizona 